\title{
SIGNIFICADOS DA PRÁTICA EDUCATIVA EM UNIDADE DE DESINTOXICAÇÃO QUÍMICA
}

Maria Helena Gehlen¹, Silomar Ilha², Rossana da Rosa Walter², Maristel Kasper Grando4, Juliana Silveira Colomé ${ }^{5}$ Dirce Stein Backes ${ }^{6}$

RESUMO: O presente estudo objetivou conhecer o significado atribuído por acadêmicos de enfermagem sobre a prática educativa desenvolvida em uma unidade de desintoxicação química. Trata-se de uma pesquisa exploratória, descritiva, de caráter qualitativo, desenvolvida com 40 acadêmicos de uma instituição privada de ensino superior da Região Central do Rio Grande do Sul, no período de agosto a dezembro de 2010. Os dados analisados resultaram nas categorias: Atribuindo significado à prática educativa e A expressão subjetiva da prática educativa na promoção do autocuidado. Os significados da prática educativa dos acadêmicos apontam para uma possível mudança de paradigma no que se refere à formação de enfermeiros para atuarem como educadores em saúde e sinalizaram para experiências subsidiadas por enfoques participativos que previam o envolvimento ativo de todos os atores sociais envolvidos. Nesta direção, enfatiza-se a necessidade do ensino oportunizar vivências práticas alicerçadas em referencial crítico-reflexivo acerca da dimensão educativa na atuação dos enfermeiros.

DESCRITORES: Drogas ilícitas; Crack; Educação em saúde; Enfermagem.

\section{MEANINGS OF EDUCATIONAL PRACTICE IN A CHEMICAL DETOXIFICATION CENTER}

ABSTRACT: The present study aimed to investigate the meaning attributed by student nurses regarding educational practices undertaken in a chemical detoxification center. It is exploratory, descriptive, qualitative research, carried out with 40 students from a private higher education institution in the Central Region of Rio Grande do Sul, in the period August - December 2010. The analyzed data resulted in the following categories: Attributing meaning to educational practice and The subjective expression of educational practice in the promotion of self-care. The students' meanings for the educational practice indicate a possible change of paradigm regarding the training of nurses to act as health educators, and show the need for experiences supported by participative approaches which require the active involvement of all the social actors involved. In this regard, the need is stressed for teaching to provide practical experiences based in in a critical-reflexive framework regarding the educational dimension in the work of nurses. DESCRIPTORS: Illicit drugs; Crack; Health education; Nursing.

\section{SIGNIFICADOSDE LAPRÁCTICAEDUCATIVAENUNIDADDEDESINTOXICACIÓNQUÍMICA}

RESUMEN: Este estudio se propuso a conocer el significado atribuido por académicos de enfermería a la práctica educativa desarrollada en una unidad de desintoxicación química. Es una investigación exploratoria, descriptiva, de carácter cualitativo, desarrollada con 40 académicos de una institución privada de enseñanza superior de la Región Central de Rio Grande do Sul, en el periodo de agosto a diciembre de 2010. Los datos analizados resultaron en las categorías: Atribuyendo significado a la práctica educativa y La expresión subjetiva de la práctica educativa en la promoción del autocuidado. Los significados de la práctica educativa de los académicos apuntan para un posible cambio de paradigma en lo que se refiere a la formación de enfermeros en el trabajo como educadores en salud y apuntan aún para experiencias subsidiadas por enfoques participativos que preveían la inclusión activa de todos los atores sociales involucrados. Así, se enfatiza la necesidad de la enseñanza dar oportunidades de vivencias prácticas basadas en referencial crítico y reflexionado acerca de la dimensión educativa en la actuación de los enfermeros. DESCRIPTORES: Drogas ilícitas; Crack; Educación en salud; Enfermería.

\footnotetext{
${ }^{1}$ Enfermeira. Mestre em Educação. Professora do Curso de Graduação em Enfermagem do Centro Universitário Franciscano - UNIFRA. Especializanda em Educação Inclusiva pela UNIFRA. Membro do Grupo de Estudos e Pesquisa em Empreendedorismo Social da Enfermagem e Saúde-GEPESES.

${ }^{2}$ Enfermeiro. Especialista em Urgência, Emergência e Trauma. Mestrando pelo Programa de Pós-Graduação em Enfermagem da Universidade Federal do Rio Grande - FURG. Bolsista CAPES. Membro do GEPESES.

${ }^{3}$ Enfermeira. Especializanda em Enfermagem Materno Infantil pelo Hospital Moinhos de Vento de Porto Alegre-RS.

${ }^{4}$ Enfermeira. Mestre em Enfermagem. Professora das Faculdade Integradas de Taquara.

${ }^{5}$ Enfermeira. Mestre em Enfermagem. Doutoranda em Enfermagem pela FURG. Professora da UNIFRA. Membro do GEPESES.

${ }^{6}$ Enfermeira. Doutora em Enfermagem. Professora da UNIFRA e da FURG. Líder do GEPESES.
}

Autor correspondente:

Recebido: 25/07/2012

Maria Helena Gehlen

Aprovado: 04/04/2013

Centro Universitário Franciscano

Rua São José, 360 - 97010-460 - Santa Maria-RS-Brasil

E- mail: mahgehlen@terra.com.br 


\section{INTRODUÇÃO}

O ensino, na área da Enfermagem, deve oferecer condições para que o acadêmico desenvolva a competência da educação em saúde por meio da prática educativa nas instituições; deve possibilitar a construção da autonomia profissional em conjunto com consciência da comunidade e coletividade. Nas instituições de saúde, o hospital aparece como um cenário complexo para o desenvolvimento da educação em saúde, principalmente ao se considerar as unidades de desintoxicação química como uma oportunidade de vivenciar a humanização nos serviços do Sistema Único de Saúde (SUS).

Neste cenário, a prática educativa em unidade de desintoxicação, com atitudes proativas, estabelecendo vivencias dialógicas com um enfoque transformador, oportuniza o cuidado de si e do outro ao expressar a subjetividade singular do cuidar por meio do sorriso, do carinho, da atenção, do toque afetivo, do olhar empático e da conversa atenciosa ${ }^{(1)}$. O ensino envolve um processo participativo e interativo em que o acadêmico de enfermagem assume a condição de sujeito de sua aprendizagem, em processo de construção de sua realidade histórico-social e em permanente interação com outros, pois é um ser simultaneamente social, histórico, político, cultural, ético e estético ${ }^{(2)}$.

$\mathrm{Na}$ medida em que essa consciência avança da condição ingênua para a crítica, na ação sobre o mundo, o homem cria o domínio da cultura e da história, tornando-se um ser da práxis concebida como reflexão e ação verdadeiramente transformadora da realidade. Dessa permanente ação transformadora, o homem, cria a história e torna-se ser histórico-social ${ }^{(3)}$.

Nessa perspectiva, toda a prática educativa deve, necessariamente, estar precedida de reflexão sobre o homem e de uma análise do meio de vida do educando; isto é, a quem o educador quer ajudar a educar. Todas as concepções de Paulo Freire estão sob a orientação dessa primeira suposição ${ }^{(3)}$. Os atos, ações, gestos, aspirações e expectativas dos acadêmicos de enfermagem que desenvolvem a prática educativa norteiam a transformação do cenário de aprendizagem, construindo a sua autonomia e desconstruindo o cotidiano do ensino que, muitas vezes, ainda privilegia os aspectos técnicos do cuidado.

A prática educativa transformadora inicia-se com o despertar do acadêmico ao aprender a conhecer o seu saber profissional e se desenvolve em uma complexidade que considera a essência das dimensões do ser humano, aspirações e expectativas singulares, bem como as cer- tezas e incertezas, ordem e desordem, e outros aspectos relacionados à construção do conhecimento ${ }^{(4)}$.

Com estas considerações sobre o desenvolvimento da prática educativa como transformação da realidade em uma relação dialógica de saberes, originou-se a indagação: qual o significado da prática educativa para acadêmicos de enfermagem que desenvolvem atividades de promoção do autocuidado em uma unidade de desintoxicação química?

Na expectativa de possibilitarnovos olhares, interativos e comprometidos com o ensino crítico-reflexivo da práxis de enfermagem em um contexto real, objetiva-se conhecer o significado da prática educativa desenvolvida pelo acadêmico de enfermagem em unidade de desintoxicação.

\section{MÉTODO}

Trata-se de uma pesquisa exploratória, descritiva, de abordagem qualitativa, realizada com acadêmicos do Curso de Graduação em Enfermagem que desenvolveram a prática educativa, na promoção do autocuidado, durante a sua formação profissional em unidade de desintoxicação química.

O cenário de operacionalização da pesquisa foi um hospital público de médio porte, o qual também tem como característica ser colaborador do ensino superior no desenvolvimento do exercício profissional. Está localizado na Região Central do Rio Grande do Sul. A Unidade de Desintoxicação Química possui aproximadamente 24 leitos, integram o serviço de atenção ao usuário de crack um médico psiquiatra, um enfermeiro, uma psicóloga, uma assistente social, um técnico em informática, 8 técnicos em enfermagem, uma pedagoga e um higienista. A unidade conta com a participação de docentes e discentes de 7 cursos de graduação: Enfermagem, Pedagogia, Psicologia, Nutrição, Fisioterapia, Terapia Ocupacional e Serviço Social.

Elegeram-se como critério de inclusão: ser acadêmico de Enfermagem e estar cursando o terceiro semestre, pois é neste período que os discentes vivenciam suas primeiras experiências curriculares teórico-práticas. Os participantes deveriam estar regularmente matriculado na Disciplina Semiologia e Semiotécnica; foram excluídos os que estavam de atestado, perfazendo um total 40 participantes.

As atividades foram desenvolvidas pelos graduandos durante os meses de agosto a dezembro de 2010. Os acadêmicos, distribuídos em grupos de seis, semanalmente desenvolveram a prática educativa estimulando o autocuidado da pessoa hospitalizada por meio de analogias de músicas, jogos e embelezamento estético. 
No mesmo período, também coletou-se os dados, por meio de uma entrevista semiestruturada elaborada pelos autores do estudo. O instrumento de coleta de dados contemplou as seguintes questões norteadoras: Qual o significado da prática educativa no desenvolvimento profissional do acadêmico de enfermagem em unidade de desintoxicação? Quais características se expressam no seu desenvolvimento profissional ao promover a prática educativa na promoção do autocuidado?

Os dados foram analisados e categorizados seguindo a análise de conteúdo ${ }^{(5)}$, a partir de pré-análise. Primeiramente organizou-se o material coletado e procedeu-se a sistematização das ideias através de leitura meticulosa das respostas obtidas na entrevista. Relacionaram-se as respostas que mais se repetiram para a discussão dos resultados, classificando-as por agrupamento entre os discursos comuns existentes formando as unidades de registro. Após, realizou-se a interpretação das categorias, buscando compreender a vivência dos entrevistados, a partir das experiências dos pesquisadores, e relacionando-as ao objetivo do estudo.

Foram considerados os preceitos éticos e legais que envolvem a pesquisa com seres humanos, conforme resolução 196/96 do Conselho Nacional de Ética em Pesquisa ${ }^{(6)}$. Assim, foi distribuído anteriormente o Termo de Consentimento Livre e Esclarecido para os participantes da pesquisa, sendo este em duas vias, ficando uma em poder do participante e outra em poder do pesquisador. Manteve-se o anonimato dos depoentes e os mesmos foram identificados por nomes de anjos. A pesquisa obteve a autorização institucional e aprovação pelo Comitê de Ética em Pesquisa do Centro Universitário Franciscano sob o número 072.2010.2.

\section{RESULTADOS}

A partir dos depoimentos dos acadêmicos de Enfermagem participantes do estudo e da existência de subsídios para a análise, emergiram duas categorias a seguir apresentadas.

\section{Atribuindo significado à prática educativa}

A prática educativa possibilitou recriar a realidade de inserção do acadêmico ao engajar seu saber-fazer transformador desconstruindo o saber-fazer profissional comumente reducionista, centrado no ensino em prol do tecnicismo para o cuidado dos agravos e enfermidades. Os acadêmicos de enfermagem expressaram a sua competência de educar em saúde com responsabilidade coletiva para conhecer e saber-fazer no seu desenvolvimento profissional, construindo a sua autonomia no cenário de aprendizagem, a seguir as falas:

Desenvolver a prática educativa foi difícil tínhamos que nos encontrar fora do horário para o planejamento. Mas desejávamos fazer tínhamos como missão proporcionar o bem estar, criamos vínculo com ética, motivando para a reabilitação de maneira que incentivamos o autocuidado. (Anjo Gabriel)

[...] foi bom realizarmos as atividades educativas, estimulamos para que eles se cuidassem. (Anjo Rafael)

Aqui foi possivel aprender a cuidar e ajudar. Acho que aprendemos a valorizar a vida e ensinamos cuidados básicos de higiene e, principalmente, de amor à vida. (Anjo Ismael)

O reconhecimento da prática educativa transformadora se aliou ao desejo de organizar, planejar e desenvolver um saber-fazer compartilhado e compromissado com a valorização do cuidado para si e o outro. O que qualifica reconstrói novas formas de cuidar, nas quais se exigem as diretrizes curriculares em superação ao reducionismo curativo e individual do fazer profissional. A prática educativa transformadora para os acadêmicos de enfermagem, foi revelada pelo seu desejo manifestado nos vínculos formados com escuta e diálogo de saberes entre pessoa cuidada e equipe. Percebeu-se as múltiplas possibilidades desses expressarem a subjetividade do saber-fazer profissional em seu um contexto de inserção:

A prática educativa aqui na unidade foi desafiadora, porque criamos atividades para o bem-estar, e $o$ autocuidado. Foi transformador, porque também estimulamos a vontade de que a pessoa em se cuidar respeitando as suas crenças e valores. (Anjo Rafael)

Quando fomos desenvolver a nossa prática educativa, pensávamos no que poderíamos contribuir na vida deles. E quando operacionalizamos sentimos que é importante respeitar o ser humano em suas fragilidades, como a de ser usuário de crack. (Anjo Miguel)

Difícil foi não ter medo na hora de entrar na unidade porque achava que ali tinha criminosos. Escutar atentivamente e planejar junto com eles foi um grande aprendizado, senti que contribui com a vida deles. (Anjo Daniel) 
Percebeu-se que a significação da prática educativa para os acadêmicos é transformadora, pois ao reconstruírem o cenário de aprendizagem no seu desenvolvimento profissional foram sujeitos no aprender a saber e fazer profissional, com autonomia e ética ao demonstrarem caminhos para que as pessoas cuidadas durante a hospitalização, pudessem realizar seu autocuidado .

\section{A expressão subjetiva da prática educativa na pro- moção do autocuidado}

Identifica-se nos discursos as mudanças na formação do enfermeiro com elementos que se expressaram na subjetividade. A análise dos dados demonstra uma desconstrução das metodologias tradicionais do ensino de enfermagem que sustentam as práticas no cuidado em saúde hegemônico, que muitas vezes se refletem no saber-fazer profissional, centrado na doença no cenário de hospitalização:

Fiquei surpreendida, sensibilizada a implementar a prática educativa. Nós utilizamos massas de brigadeiro e beijinho e também acessórios decorativos promovendo o autocuidado de uma forma lúdica. (Anjo Ariel)

[...] levamos um violão e cantamos juntos para que trouxesse alegria e acolhimento ao ambiente. (Anjo Nataniel)

Nós fizemos uma gincana para que eles percebessem que a união e a alegria são atributos para que houvesse a aceitação da condição de realizar desintoxicação química. (Anjo Muriel)

Ao expressar a sua subjetividade no desenvolvimento da prática educativa, acadêmico de enfermagem vivenciou o sentimento de pertencer a uma coletividade ao reconhecer no outro as suas possibilidades para transformar um cenário que estimulasse o autocuidado e o cuidado de si:

Fizemos uma paródia em analogia a uma música e depois um momento de leitura para que as pessoas pudessem desenvolver o autocuidado [...]. (Anjo Gabriel)

[...] na paródia expressávamos a alegria. Estávamos caracterizados com objetos lúdicos. (Anjo Muriel)

[...] muitos se emocionaram, outras pessoas sorriam e cantavam empolgadas em se cuidar. Pudemos viver isso aqui no hospital, eu nem imaginava! (Anjo Natanael)
Evidenciou-se, nos discursos, a importância da prática educativa como essência para a subjetividade com suas expressões na promoção do autocuidado que não foi focado apenas no agravo, pois transcendeu uma barreira do saber-fazer mecanizado. À medida que se reporta às necessidades reais do ser humano, como a autoestima, o bem estar, o cotidiano hospitalar, vivenciado pela sua internação, considera as condições físicas, emocionais e espirituais do ser cuidado.

\section{DISCUSSÃO}

No ensino de Enfermagem muitas vezes ainda se percebe a vivência acadêmica centrada em conteúdos disciplinares, que solidificam as certezas, já que pouco se indaga em como cuidar de si e do outro em suas múltiplas dimensionalidades. O cuidado humanizado não significa a rejeição aos aspectos técnicos e científicos; a intenção ao revelar o cuidado é enfatizar a característica do processo interativo e de trocas de energia criativa, emocional e intuitiva, que compõe o lado artístico além do aspecto moral ${ }^{(7)}$.

$\mathrm{Na}$ prática docente é necessário que esteja em jogo um repertório de recursos, como conhecimentos, capacidades cognitivas e capacidades relacionais. A prática da autoformação deve resultar, idealmente, de uma prática reflexiva no desenvolvimento de seu ofício enquanto docente, constituindo-se em fonte de aprendizagem e de regulação e tornando-se uma alavanca essencial na construção de novas competências e novas práticas ${ }^{(8)}$.

Os cenários de atuação do enfermeiro são amplos e devem ser explorados de maneira a dar visibilidade a esta categoria profissional. As práticas educativas desenvolvidas no campo da saúde têm sido nomeadas de formas diversas, as quais estão relacionadas à história da Educação e Saúde e à forma como essas práticas têm sido apropriadas ${ }^{(9)}$. Os profissionais que atuam nos cenários de saúde necessitam investir nessa diversidade dos campos de atuação, e para isso devem reconstruir os paradigmas que participam das questões de saúde, sendo salientada a profissão de enfermeiro.

Neste aspecto salientam-se os setores que apresentam maior vulnerabilidade social, como é o caso das unidades de desintoxicação química, que necessitam de uma atuação que venha ao encontro da educação em saúde transformadora. A vulnerabilidade do dependente químico está associada a um processo de exclusão, discriminação que sofrem ou enfraquecimento de grupos e comunidades fragilizadas, tanto na promoção e 
proteção da saúde, quanto na garantia dos seus direitos de cidadania ${ }^{(10)}$.

Tudo isso deve estar relacionado à ideia de que a promoção de saúde não ocorre somente em hospitais, pronto-atendimentos, ambulatórios, clínicas, dentre outros, mas sim, transcende os espaços onde, ocasionalmente, a doença já está instalada. As experiências do estudante de Enfermagem são um processo de socialização na profissão e contribuem, significativamente, para a formação de um perfil profissional ${ }^{(11)}$.

Nessa perspectiva, todo saber implica um processo de aprendizagem e de formação, e na medida em que um saber é desenvolvido, mais se revela longo e complexo o processo de aprendizagem. Este, por sua vez, necessita de estratégias e sistematização adequadas. Assim, a produção de novos saberes nas universidades pressupõe um processo de formação. Tal processo deve ser fundamentado tanto em conhecimentos já existentes, como na revisão permanente de possibilidades para as práticas pedagógicas, uma vez que o processo educativo precisa ser, constantemente, renovado e ressignificado ${ }^{(12)}$.

A educação em saúde é uma competência na formação do acadêmico de Enfermagem, que deve ser problematizada no cotidiano do ensino de maneira dialógica entre os saberes dos dependentes químicos e dos acadêmicos. Portanto, a educação necessita estar pautada no compromisso em empregar estratégias que proporcionem efetivamente a participação dos sujeitos a partir do compartilhamento de saberes que advém de suas vivências ${ }^{(13)}$. Pode-se dizer que as práticas educativas desenvolvidas por enfermeiros mantêm um enfoque educativo-preventivo, muitas vezes sem incorporar a compreensão dos fatores determinantes dos problemas de saúde ou ainda, as necessidades e saberes da população, mas mesmo assim, dando maior atenção à saúde do indivíduo.

Com as modificações ocorridas na Enfermagem ao longo de sua história, evidencia-se como uma das principais características adquiridas pelo enfermeiro contemporâneo a tomada de decisão, ou seja, o enfermeiro atualmente deve ser prospectivo e pró-ativo. Estas características subsidiam o profissional para coordenar situações e grupos de diferentes formas na área da saúde, continuamente primando por um trabalho em equipe almejando os mesmos objetivos.

No que concerne a prática educativa desenvolvida pelos acadêmicos, pode-se dizer que foi transformadora no cenário de aprendizagem, promovendo a liberdade de expressar a subjetividade presente no ato de recriar e educar para a promoção do autocuidado. $\mathrm{Na}$ análise dos discursos se evidenciou a singularidade de cada sujeito, por meio de sorrisos, alegorias, caracterizações, toque e comunicação terapêutica.

\section{CONSIDERAÇÕES FINAIS}

As concepções dos acadêmicos relacionadas à prática educativa que se efetiva nos diferentes espaços de inserção profissional ao longo do Curso de Enfermagem sinalizam para experiências subsidiadas por enfoques participativos, que previam o envolvimento ativo de todos os atores sociais envolvidos. Com base nas reflexões advindas da literatura e dos argumentos dos acadêmicos, a prática educativa configura-se como elemento central do processo formativo do enfermeiro e requer reflexão permanente no interior dos cursos de graduação a fim de que esse ser/fazer esteja cada vez mais próximo da atenção integral, humanizada e de qualidade.

Nesse sentido, emergiram significados que apontaram a necessidade de se considerar a complexidade do ensino de Enfermagem sobre a realidade do saber-fazer profissional como sustento à transformação com flexibilidade, subjetividade e reconhecimento dos valores que constituem o ser humano. Para desenvolverem a prática educativa transformadora construíram relações interpessoais dos sujeitos que se educam ao aprender a cuidar, em contrapartida às práticas do ensino de conteúdos $\mathrm{e}$ ao tecnicismo. Este muitas vezes expresso nas rotinas tecnicista do saber fazer profissional individual e curativo.

Nesta perspectiva, visualiza-se a necessidade de que os cursos de Enfermagem revejam seus processos formativos no sentido de oportunizar vivências práticas, alicerçadas em referenciais crítico-reflexivos acerca da dimensão educativa. Nesta direção, considerando que as questões que envolvem a prática educativa em saúde possuem componentes amplos e interrelacionados e que, portanto, não deveriam ser abordados por meio de estratégias individualizantes, destacam-se as experiências mencionadas como exemplos de formas mais participativas.

Os significados da prática educativa dos acadêmicos contribuem para uma possível mudança de paradigma no que se refere à formação de enfermeiros para atuarem como educadores em saúde. Os resultados deste estudo poderão auxiliar e ampliar a compreensão a respeito da prática educativa como transformação da realidade em uma relação dialógica de saberes do acadêmico de Enfermagem na promoção do autocuidado e no cuidado ao dependente químico. 
A obtenção desses dados e suas análises poderão subsidiar o desenvolvimento de novas pesquisas relacionadas ao processo educativo em que o sujeito é educado enquanto cuida, fato que corrobora para uma educação transformadora. Poderão ainda auxiliar o docente no processo de ensino aprendizagem que instigue o acadêmico a ser sujeito do seu próprio aprendizado, ao passo que leve em conta as suas vivências, bem como as vivências daqueles que estão aos seus cuidados.

\section{REFERÊNCIAS}

1. Siqueira DF, Moreschi C, Backes DS, Lunardi VL, Filho WDL, Dalcin CB. Repercussões do uso de crack no cotidiano familiar. Cogitare enferm. [Internet] 2012;17(2) [acesso em 20 ago 2012]. Disponível: http://ojs.c3sl.ufpr.br/ojs2/index.php/cogitare/article/ view $/ 23518$

2. Souza R, Shimizu HE. Análise da implementação da sistematização da assistência de enfermagem em uma unidade de reabilitação. Rev Bras Enferm. [Internet] 2010;63(2) [acesso em 20 ago 2012]. Disponível: http:// dx.doi.org/10.1590/S0034-71672010000200009

3. Freire P. Pedagogia da esperança. $15^{\mathrm{a}}$ ed. São Paulo: Paz e Terra; 2008.

4. Morin E. Cabeça bem-feita: repensar a reforma, reformar o pensamento. $17^{\mathrm{a}} \mathrm{ed}$. Rio de Janeiro: Bertrand Brasil; 2010.

5. Bardin L. Análise de conteúdo. $4^{\mathrm{a}}$ ed. Lisboa: Edições; 2009.

6. Ministério da Saúde (BR). Conselho Nacional de Saúde. Diretrizes e normas regulamentadoras de pesquisa envolvendo seres humanos. Resolução n. 196, de 10 de outubro de 1996. Brasília; 1996.

7. Magalhães JB. A humanização na prática de enfermeiros em unidade hospitalar de clínica médico cirúrgica [dissertação]. São Paulo (SP): Universidade Federal de São Paulo; 2008.

8. Serra MN. Aprender a ser enfermeiro. Identidade profissional em estudantes de enfermagem. Rev cienc. educ. [Internet] 2008;5(1) [acesso em 20 ago 2012]. Disponível: http://sisifo.fpce.ul.pt/?r=15\&p=69.

9. Acioli S. A prática educativa como expressão do cuidado em Saúde Pública. Rev Bras Enferm. [Internet] 2008;61(1) [acesso em 20 ago 2012]. Disponível: http:// dx.doi.org/10.1590/S0034-71672008000100019.
10. Nichiata LYI, Bertolozzi MR, Takashi RF, Fracolli LA. The use of the "vulnerability" concept in the nursing area. Rev. Latino-Am. Enfermagem. [Internet] 2008;16(5) [acesso em 20 ago 2012]. Disponível: http:// www.ncbi.nlm.nih.gov/pubmed/19061032.

11. Ito EE, Peres AM, Takahashi RT, Leite MMJ. O ensino de enfermagem e as diretrizes curriculares nacionais: utopia x realidade. Rev Esc Enferm USP. [Internet] 2009;40(4) [acesso em 20 ago 2012]. Disponível: http:// dx.doi.org/10.1590/S0080-62342006000400017.

12. Maderia MZ, Lima MGSB. O significado da prática docente na constituição do saber ensinar das professoras do Curso de Enfermagem da Universidade Federal do Piauí. Texto Contexto Enferm. [Internet] 2010;19(1) [acesso em 20 ago 2012]. Disponível: http://dx.doi. org/10.1590/S0104-07072010000100008.

13. Gehlen MH, Bertolino KCO, Perlin APB, Machedo AT, Moura A, Ziegler FS et al. Acolhimento: um instrumento na promoção da educação sobre a saúde transformadora. In: Backes DS, organizadora. Empreendedorismo Social da enfermagem: rupturas e avanços. Santa Maria: Centro Universitário Franciscano; 2012. p. 115-31.

Cogitare Enferm. 2013 Abr/Jun; 18(2):317-22 